\title{
Calcium/Calmodulin-Dependent Protein Kinase II: An Unforgettable Kinase
}

\author{
Leslie C. Griffith \\ Department of Biology and Volen Center for Complex Systems, Brandeis University, Waltham, Massachusetts 02454-9110
}

Key words: calcium; calmodulin; learning; localization; LTP; NMDA; phosphatase; protein kinase; knock-out mice

\section{The search for "memory molecules" and why CaMKII is an appealing candidate}

Since the time neuroscientists first recognized that biochemical events inside neurons could influence the function of the brain, there have been people looking for "memory molecules." This elusive ion, small molecule, protein, or nucleic acid would be the keystone on which memory was built; understanding the memory molecule would allow us to unlock the mysteries of cognition. Models of how this molecule could work abounded, but the idea of a memory molecule as a kinase/phosphatase-based molecular switch emerged as an important contender (Lisman, 1985). The discovery that there actually was an abundant neuronal protein kinase that had switch-like properties (Miller and Kennedy, 1986) was met with great enthusiasm, and the role of calcium/ calmodulin-dependent protein kinase II (CaMKII) in learning and memory has been studied intensively. This series of reviews will cover recent advances in our understanding of the regulation of CaMKII and its autophosphorylation by phosphatases and localizing interactions, its involvement in synaptic plasticity, and the advent of mammalian genetic models for the study of CaMKII in behavior.

\section{CaMKII is a ubiquitous, high-abundance signaling molecule} CaMKII is a serine/threonine kinase with a broad range of substrates. Since its activity was first described in the late 1970 s (Schulman and Greengard, 1978), over 1200 papers have been published that feature the kinase in their title. These studies have provided a solid understanding of the gross structure and enzymatic properties of the kinase (for a recent review of the basic properties of CaMKII, see Hudmon and Schulman, 2002). CaMKII is found in most tissues, but it is present in especially high concentrations in neurons, in which it may be up to $2 \%$ of total protein in some brain regions (Erondu and Kennedy, 1985). In mammals, the kinase is encoded by four genes, $\alpha, \beta, \gamma$, and $\delta$, with the $\alpha$ and $\beta$ isozymes predominant in the brain. Each of these isozymes has multiple splice variants. In invertebrate species in which the genome is sequenced, a single alternatively spliced gene encodes the kinase.

CaMKII monomers assemble into a large holoenzyme. Mono-

Received July 16, 2004; revised Aug. 25, 2004; accepted Aug. 25, 2004.

This work was supported by National Institutes of Health Grant R01 GM54408.

Correspondence should be addressed to Leslie C. Griffith, Department of Biology, MS008, Brandeis University,

415 South Street, Waltham, MA 02454-9110. E-mail: griffith@brandeis.edu.

DOI:10.1523/JNEUROSCI.2888-04.2004

Copyright $\odot 2004$ Society for Neuroscience $\quad$ 0270-6474/04/248391-03\$15.00/0 mers of different isozymes are able to coassemble, allowing for a large number of possible holoenzyme compositions. Measurement of the Stoke's radii and sedimentation coefficients of rat brain and Drosophila CaMKIIs suggested a holoenzyme of 8-12 subunits (Bennett et al., 1983; Kuret and Schulman, 1984; GuptaRoy and Griffith, 1996). Early electron microscopic studies of CaMKII purified from rat brain found some heterogeneity in holoenzyme size, reporting both 8 and 10 subunit particles (Kanaseki et al., 1991). More recent single-particle studies, using recombinant rat CaMKII, have provided much higher-resolution (21-25 А) images (Kolodziej et al., 2000; Gaertner et al., 2004). These studies indicate that homomers of $\alpha, \beta, \gamma$, and $\delta$ are capable of forming dodecamers that are dimers of hexameric rings, with the $\mathrm{N}$-terminal catalytic domains extending off of a gear-like core made up of association domains. To date, no highresolution $\mathrm{x}$-ray structure is available for the CaMKII holoenzyme. An association domain fragment has been crystallized and was found to form a tetradecamer (Hoelz et al., 2003). The difference in subunit number between the single particle and $\mathrm{x}$-ray structures is not understood but may indicate that the kinase has multiple possible holoenzyme configurations.

The high abundance of CaMKII in the nervous system makes it an unusual enzyme; most catalytic molecules are present in relatively low amounts. CaMKII is now recognized to inhabit many different subcellular structures and compartments. Neurons are complicated cells, and, as our knowledge of cell biology expands, the number of specialized subcellular domains that can be identified is increasing. Targeting of signaling molecules to particular structures within the cell can constrain their function. For CaMKII, localization is a dynamic process that is likely to be critical for the role of the kinase in synaptic plasticity. Recent advances in our understanding of the dynamic control of localization are presented in the mini-review by Schulman (2004).

\section{The many modes of CaMKII activity regulation}

The regulation of CaMKII activity has turned out to be much more than a simple function of the levels of $\mathrm{Ca}^{2+} / \mathrm{CaM}$. Investigation of the localization of the kinase and its association with other proteins has led to the finding that CaMKII activity can be regulated by a subset of these binding interactions. Several CaMKII binding proteins have been found that can maintain the active state of the kinase in the absence of $\mathrm{Ca}^{2+} / \mathrm{CaM}$, and one binding partner has been identified that inactivates the kinase by stimulating inhibitory autophosphorylation. The mechanisms of classical regulation of the kinase by $\mathrm{Ca}^{2+} / \mathrm{CaM}$ and more recently 
discovered forms of regulation by CaMKII-binding proteins are explored in the mini-review by Griffith (2004).

The much-touted switch-like properties of CaMKII come from its ability to be autophosphorylated within its regulatory domain. Phosphorylation of $\mathrm{Thr}^{286}$ in the rat $\alpha$ CaMKII isozyme enables the kinase to remain active even after dissociation of $\mathrm{Ca}^{2+} / \mathrm{CaM}$, its normal activator (Miller et al., 1988; Schworer et al., 1988; Thiel et al., 1988; Lou and Schulman, 1989). Once the enzyme is calcium-independent and $\mathrm{Ca}^{2+} / \mathrm{CaM}$ dissociates, additional autophosphorylation sites within the CaM-binding domain become accessible and are autophosphorylated; these sites block rebinding of $\mathrm{Ca}^{2+} / \mathrm{CaM}$. CaMKII autophosphorylation reactions have been studied quite extensively and are critical to regulation of the kinase by both $\mathrm{Ca}^{2+} / \mathrm{CaM}$ and other newly characterized protein regulators. The reversal of autophosphorylation by the activity of various cellular phosphatases is an important regulator of the lifetime of these autophosphorylated species. The influence of locally tethered phosphatase activity on plasticity is covered in the mini-review by Colbran (2004).

\section{CaMKII is critical for synaptic and behavioral plasticity}

The role of CaMKII in neuronal function has been studied at both cellular and behavioral levels using pharmacological and genetic manipulations. CaMKII activity is required for induction of long-term potentiation (LTP) in the CA1 region of the hippocampus (Malenka et al., 1989; Malinow et al., 1989; Silva et al., 1992a). LTP is a reflection of the increases in synaptic strength that can occur with high-frequency or paired stimulation and is believed to be a cellular correlate of memory (for a recent review, see Malenka, 2003). Defects in LTP often accompany impairments in spatial learning, and animals that lack the $\alpha$ CaMKII isozyme do not learn normally in such tasks (Silva et al., 1992b, 1996; Elgersma et al., 2002). The switch-like features of CaMKII also appear to have importance for synaptic plasticity. Autophosphorylation of $\mathrm{Thr}^{286}$ is persistently increased after stimuli that induce LTP (Fukunaga et al., 1993, 1995; Barria et al., 1997; Ouyang et al., 1997), and knock-in of a T286A $\alpha$ CaMKII mutation that prevents generation of autonomous activity blocks CA1 LTP and learning in the Morris water maze (Giese et al., 1998). Contextual fear conditioning can also induce autophosphorylation of $\alpha$ CaMKII (Atkins et al., 1998; Rodrigues et al., 2004).

Genetic manipulation of $\alpha$ CaMKII has led the way for use of engineered mice in neuroscience research. The depth of understanding of the biochemistry of the regulation of CaMKII has allowed very precise manipulations of regulatory aspects of the kinase to be performed by replacement of the wild-type gene with mutant forms of the kinase in knock-in mice. By crippling only a single aspect of kinase function, these manipulations have given us insight into the importance of specific autophosphorylation sites and of $\alpha$ CaMKII mRNA localization. The mini-review by Elgersma et al. (2004) documents the significance of these genetic models for understanding the role of CaMKII in brain function.

\section{Is CaMKII a memory molecule?}

The evidence that CaMKII is involved in memory formation is quite convincing and comes from multiple vertebrate (Zhao et al., 1999; Gleason et al., 2003) (mouse and rat studies reviewed in this series) and invertebrate (Saitoh and Schwartz, 1985; Griffith et al., 1993) species. At one level, this would suggest that CaMKII is a memory molecule. There are, however, many other molecules for which similar evidence has been found. In the protein kinase family alone, ERK (extracellular signal-regulated kinase), protein kinase C, cAMP-dependent protein kinase (for review, see
Selcher et al., 2002), cdk5 (cyclin-dependent kinase 5) (Fischer et al., 2003), and both receptor (trkB and Eph receptor) and nonreceptor (Src) tyrosine kinases (Purcell and Carew, 2003) have all been shown to be required for formation of some types of memory. By this most simple (and inadequate) definition, all of these proteins are memory molecules. Formulation of a definition for what a memory molecule would be is a difficult challenge itself, and it is important to resist the impulse to build the definition around the favorite candidates.

A more germane and 21st century question is whether there actually are memory molecules at all. All of the proteins that have been found to be required for LTP and spatial learning also have other, nonlearning roles. For some, such as actin (Kim and Lisman, 1999), these other functions are clearly their raison d'etre. The idea that a single molecule is the repository of memory also seems naive in the face of our current understanding of the cell biology of the neuron. Signal transduction research has been transformed by the idea of compartmentalization and macromolecular complex formation. Plasticity in the brain is also clearly associated with short-term and long-term changes in cellular and subcellular architecture (Muller et al., 2002). For $\alpha$ CaMKII, the most relevant subcellular structure is likely to be the postsynaptic density. Understanding how CaMKII is required for memory formation will be intimately tied to understanding the reciprocal regulation of CaMKII and its interacting partners within this structure. Despite these complexities and the pressing need for additional experimentation, as the following mini-review series illustrates, our understanding of synaptic plasticity and memory formation has been greatly enhanced by nearly two decades of discoveries concerning the roles and regulation of CaMKII in the nervous system.

\section{References}

Atkins CM, Selcher JC, Petraitis JJ, Trzaskos JM, Sweatt JD (1998) The MAPK cascade is required for mammalian associative learning. Nat Neurosci 1:602-609.

Barria A, Muller D, Derkach V, Griffith LC, Soderling TR (1997) Regulatory phosphorylation of AMPA-type glutamate receptors by CaM-KII during long-term potentiation. Science 276:2042-2045.

Bennett MK, Erondu NE, Kennedy MB (1983) Purification and characterization of a calmodulin-dependent protein kinase that is highly concentrated in brain. J Biol Chem 258:12735-12744.

Colbran RJ (2004) Protein phosphatases and calcium/calmodulindependent protein kinase II-dependent synaptic plasticity. J Neurosci 24:8404-8409.

Elgersma Y, Fedorov NB, Ikonen S, Choi ES, Elgersma M, Carvalho OM, Giese KP, Silva AJ (2002) Inhibitory autophosphorylation of CaMKII controls PSD association, plasticity, and learning. Neuron 36:493-505.

Elgersma Y, Sweatt JD, Giese KP (2004) Mouse genetic approaches to investigating calcium/calmodulin-dependent protein kinase II function in plasticity and cognition. J Neurosci 24:8410-8415.

Erondu NE, Kennedy MB (1985) Regional distribution of type II $\mathrm{Ca}^{2+} /$ calmodulin-dependent protein kinase in rat brain. J Neurosci 5:3270-3277.

Fischer A, Sananbenesi F, Spiess J, Radulovic J (2003) Cdk5: a novel role in learning and memory. Neurosignals 12:200-208.

Fukunaga K, Stoppini L, Miyamoto E, Muller D (1993) Long-term potentiation is associated with an increased activity of $\mathrm{Ca}^{2+} /$ calmodulindependent protein kinase II. J Biol Chem 268:7863-7867.

Fukunaga K, Muller D, Miyamoto E (1995) Increased phosphorylation of $\mathrm{Ca}^{2+} /$ calmodulin-dependent protein kinase II and its endogenous substrates in the induction of long term potentiation. J Biol Chem 270:6119-6124.

Gaertner TR, Kolodziej SJ, Wang D, Kobayashi R, Koomen JM, Stoops JK, Waxham MN (2004) Comparative analyses of the three-dimensional structures and enzymatic properties of alpha, beta, gamma and delta isoforms of $\mathrm{Ca}^{2+}$-calmodulin-dependent protein kinase II. J Biol Chem 279:12484-12494. 
Giese KP, Fedorov NB, Filipkowski RK, Silva AJ (1998) Autophosphorylation at Thr286 of the alpha calcium-calmodulin kinase II in LTP and learning. Science 279:870-873.

Gleason MR, Higashijima S, Dallman J, Liu K, Mandel G, Fetcho JR (2003) Translocation of CaM kinase II to synaptic sites in vivo. Nat Neurosci 6:217-218.

Griffith LC (2004) Regulation of calcium/calmodulin-dependent protein kinase II activation by intramolecular and intermolecular interactions. J Neurosci 24:8394-8398.

Griffith LC, Verselis LM, Aitken KM, Kyriacou CP, Greenspan RJ (1993) Inhibition of calcium/calmodulin-dependent protein kinase in Drosophila disrupts behavioral plasticity. Neuron 10:501-509.

GuptaRoy B, Griffith LC (1996) Functional heterogeneity of alternatively spliced isoforms of Drosophila calcium/calmodulin-dependent protein kinase II. J Neurochem 66:1282-1288.

Hoelz A, Nairn AC, Kuriyan J (2003) Crystal structure of a tetradecameric assembly of the association domain of $\mathrm{Ca}^{2+} /$ calmodulin-dependent kinase II. Mol Cell 11:1241-1251.

Hudmon A, Schulman H (2002) Neuronal $\mathrm{Ca}^{2+} /$ calmodulin-dependent protein kinase II: the role of structure and autoregulation in cellular function. Annu Rev Biochem 71:473-510.

Kanaseki T, Ikeuchi Y, Sugiura H, Yamauchi T (1991) Structural features of $\mathrm{Ca}^{2+} /$ calmodulin-dependent protein kinase II revealed by electron microscopy. J Cell Biol 115:1049-1060.

Kim CH, Lisman JE (1999) A role of actin filament in synaptic transmission and long-term potentiation. J Neurosci 19:4314-4324.

Kolodziej SJ, Hudmon A, Waxham MN, Stoops JK (2000) Threedimensional reconstructions of calcium/calmodulin-dependent (CaM) kinase II alpha and truncated CaM kinase II alpha reveal a unique organization for its structural core and functional domains. J Biol Chem 275:14354-14359.

Kuret J, Schulman H (1984) Purification and characterization of a $\mathrm{Ca}^{2+}$ / calmodulin-dependent protein kinase from rat brain. Biochemistry 23:5495-5504.

Lisman JE (1985) A mechanism for memory storage insensitive to molecular turnover: a bistable autophosphorylating kinase. Proc Natl Acad Sci USA 82:3055-3057.

Lou LL, Schulman H (1989) Distinct autophosphorylation sites sequentially produce autonomy and inhibition of the multifunctional $\mathrm{Ca}^{2+}$ / calmodulin-dependent protein kinase. J Neurosci 9:2020-2032.

Malenka RC (2003) The long-term potential of LTP. Nat Rev Neurosci 4:923-926.

Malenka RC, Kauer JA, Perkel DJ, Mauk MD, Kelly PT, Nicoll RA, Waxham MN (1989) An essential role for postsynaptic calmodulin and protein kinase activity in long-term potentiation. Nature 340:554-557.

Malinow R, Schulman H, Tsien RW (1989) Inhibition of postsynaptic PKC or CaMKII blocks induction but not expression of LTP. Science 245:862-866.

Miller SG, Kennedy MB (1986) Regulation of brain type II $\mathrm{Ca}^{2+}$ / calmodulin-dependent protein kinase by autophosphorylation: $\mathrm{Ca}^{2+}$ triggered molecular switch. Cell 44:861-870.
Miller SG, Patton BL, Kennedy MB (1988) Sequences of autophosphorylation sites in neuronal type II CaM kinase that control $\mathrm{Ca}^{2+}$-independent activity. Neuron 1:593-604.

Muller D, Nikonenko I, Jourdain P, Alberi S (2002) LTP, memory and structural plasticity. Curr Mol Med 2:605-611.

Ouyang Y, Kantor D, Harris KM, Schuman EM, Kennedy MB (1997) Visualization of the distribution of autophosphorylated calcium/calmodulindependent protein kinase II after tetanic stimulation in the CA1 area of the hippocampus. J Neurosci 17:5416-5427.

Purcell AL, Carew TJ (2003) Tyrosine kinases, synaptic plasticity and memory: insights from vertebrates and invertebrates. Trends Neurosci 26:625-630.

Rodrigues SM, Farb CR, Bauer EP, LeDoux JE, Schafe GE (2004) Pavlovian fear conditioning regulates Thr286 autophosphorylation of $\mathrm{Ca}^{2+}$ / calmodulin-dependent protein kinase II at lateral amygdala synapses. J Neurosci 24:3281-3288.

Saitoh T, Schwartz JH (1985) Phosphorylation-dependent subcellular translocation of $\mathrm{Ca}^{2+} /$ calmodulin-dependent protein kinase produces an autonomous enzyme in Aplysia neurons. J Cell Biol 100:835-842.

Schulman H (2004) Activity-dependent regulation of calcium/calmodulindependent protein kinase II localization. J Neurosci 24:8399-8403.

Schulman H, Greengard P (1978) Stimulation of brain membrane protein phosphorylation by calcium and an endogenous heat-stable protein. Nature 271:478-479.

Schworer CM, Colbran RJ, Keefer JR, Soderling TR (1988) $\mathrm{Ca}^{2+} /$ calmodulin-dependent protein kinase II: identification of a regulatory autophosphorylation site adjacent to the inhibitory and calmodulinbinding domains. J Biol Chem 263:13486-13489.

Selcher JC, Weeber EJ, Varga AW, Sweatt JD, Swank M (2002) Protein kinase signal transduction cascades in mammalian associative conditioning. The Neuroscientist 8:122-131.

Silva AJ, Stevens CF, Tonegawa S, Wang Y (1992a) Deficient hippocampal long-term potentiation in alpha-calcium-calmodulin kinase II mutant mice. Science 257:201-206.

Silva AJ, Paylor R, Wehner JM, Tonegawa S (1992b) Impaired spatial learning in alpha-calcium-calmodulin kinase II mutant mice. Science 257:206-211.

Silva AJ, Rosahl TW, Chapman PF, Marowitz Z, Friedman E, Frankland PW, Cestari V, Cioffi D, Sudhof TC, Bourtchuladze R (1996) Impaired learning in mice with abnormal short-lived plasticity. Curr Biol 6:1509-1518.

Thiel G, Czernik AJ, Gorelick F, Nairn AC, Greengard P (1988) $\mathrm{Ca}^{2+}$ / calmodulin-dependent protein kinase II: identification of threonine-286 as the autophosphorylation site in the $\alpha$ subunit associated with the generation of $\mathrm{Ca}^{2+}$-independent activity. Proc Natl Acad Sci USA 85:6337-6341.

Zhao W, Lawen A, Ng KT (1999) Changes in phosphorylation of $\mathrm{Ca}^{2+} /$ calmodulin-dependent protein kinase II (CaMKII) in processing of short-term and long-term memories after passive avoidance learning. J Neurosci Res 55:557-568. 